\title{
Avaliação da satisfação de estudantes público-alvo da educação inclusiva em cursos de pós-graduação de universidades públicas
}

\author{
Evaluation of the student satisfaction of public-inclusive \\ education in postgraduate courses of public universities
}

\author{
Ana Paula Silva Cantarelli Branco ${ }^{1}$ \\ ${ }^{1}$ Universidade Federal de São Carlos | Faculdade de Educação Especial | Departamento de \\ Psicologia São Carlos | SP | Brasil. Contato: anapaula.cantarellibranco@gmail.com \\ http://orcid.org/0000-0002-6878-3676
}

\author{
Maria Amélia Almeida² \\ ${ }^{2}$ Universidade Federal de São Carlos | Faculdade de Educação Especial | Departamento de \\ Psicologia São Carlos | SP | Brasil. Contato: ameliama@terra.com.br \\ http://orcid.org/0000-0002-8919-2330
}

Resumo: Com o aumento do número de matrículas de estudantes público-alvo da educação inclusiva no Ensino Superior de pós-graduação este estudo objetivou avaliar o nível de satisfação de estudantes públicoalvo da educação inclusiva de quatro Universidades Públicas brasileiras, sendo uma Federal e três Estaduais e analisar suas atitudes frente às condições oferecidas pelas IES. Trata-se de pesquisa exploratória cuja coleta de dados ocorreu por meio da aplicação da Escala de Satisfação e Atitudes de Pessoas com Deficiência - ESA. Participaram nove estudantes matriculados em Cursos de Mestrado e Doutorado no Estado de São Paulo. Os resultados receberam tratamento quantitativo através da mensuração da escala aplicada e análise qualitativa de determinados itens da escala. Quanto a satisfação estrutural, grande parte dos entrevistados revelaram sentirem-se insatisfeitos com a condição de acessibilidade arquitetônica das IES a que pertencem. Os níveis de satisfação operacional, no geral, aproximam-se de respostas satisfatórias cujas condições se referem a recursos de âmbito metodológico para acompanhar as aulas. Por conseguinte, no quesito voltado para a Satisfação psicoafetivas, apresentaram tendências satisfatórias nas relações interpessoais. Na Atitude frente as barreiras, aproximaram-se de respostas satisfatórias, todavia, não consideram importante acionar o Ministério Público para garantia de direitos. Conclui-se que dependendo do que as Instituições oferecerem, as falhas nos cursos superiores de Pós-graduação podem ser observadas. No entanto, as IES precisam melhorar em todos os âmbitos de satisfação com vistas a permitir maior ingresso e a permanência desses estudantes, de modo que aumentem os níveis de satisfação no ensino superior de Pós-graduação.

Palavras-chave: Educação inclusiva. Satisfação. Inclusão no ensino superior. Pós-Graduação. Universidade pública.

Abstract: Due to the increase of special education target students in Higher Education this study aimed to evaluate the level of satisfaction of such students in one federal and three state Brazilian Public Universities, and analyze their attitudes regarding the conditions offered by the HEI. In this exploratory research, data was collected through the application of the Satisfaction Scale and Attitudes of People with Disabilities - ESA. Nine master's and doctor's students in the State of São Paulo participated in the study. The results were quantitatively treated by measuring the applied scale and qualitative analysis of certain items of the scale. As for structural satisfaction, a large part of the interviewees revealed that they felt dissatisfied with the architectural accessibility of the HEI to which they belong. The levels of operational satisfaction, in general, were high in which conditions refer to resources of methodological scope to follow the lessons. Therefore, in relation to psycho-affective satisfaction, they presented satisfactory tendencies in interpersonal relationships. At Attitude, they have approached satisfactory answers, however, they do not consider it important to call the Public Prosecution Service to guarantee their rights. It is concluded that depending on what the institutions offer, failures of the courses in the postgraduate can be observed. However, HEIs need to improve in all areas of satisfaction in order to allow higher admission and stay of these students, to increase levels of satisfaction in post-graduate students in higher education.

Key words: Inclusive education. Satisfaction. Inclusion in higher education. Postgraduate studies. Public universities. 
DOI: http://dx.doi.org/10.1590/S1414-40772019000100004

Recebido em: 4 de janeiro de 2017

Aprovado em: 29 de novembro de 2018

Este é um artigo publicado em acesso aberto (Open Access) sob a licença Creative Commons Attribution Non-Commercial, que permite uso, distribuição e reprodução em qualquer meio, sem restrições desde que sem fins comerciais e que o trabalho original seja corretamente citado. https://creativecommons.org/licenses/by-nc/4.0/

\section{Introdução}

Em termos políticos e históricos, a inclusão escolar da pessoa com deficiência ${ }^{1}$, em Instituições de Ensino Superior (IES), na perspectiva brasileira, foi marcada pelo documento Desafios no Ensino Superior (BRASIL, 2000). Em seguida, por meio do movimento instituído pela Organização das Nações Unidas (ONU) evidenciou-se o Ano Internacional da Pessoa Com Deficiência (AIPD), em 1981, e também o da Instituição da Década das Nações Unidas para a Pessoa Com Deficiência. Passaram a discutir ações em virtude dessas pessoas não concluírem a Educação Básica e, assim, começou-se um movimento de ampliação de vagas para o acesso ao Ensino Superior (BRASIL, 2000).

Todavia, não havia reserva de vagas para candidatos com deficiência, ou seja, apenas os que exigiam poucas adaptações, como as de âmbito físico, eram inseridos neste nível de ensino. A partir da segunda metade da década de 1990 houve uma reforma política de crescimento das vagas de pessoas com deficiência em que o governo federal, com base na política educacional superior, deliberou a Portaria de $n^{\circ} 3.284 / 2003$ (BRASIL, 2003) a qual promoveu mudanças voltadas para a autorização, reconhecimento e credenciamento das IES.

Por meio do Aviso Circular 227/1996 (BRASIL, 1996) houve flexibilizações tanto na promoção de serviços educacionais, quanto na de infraestrutura, bem como na de capacitações de recursos humanos. A Lei Brasileira de Inclusão (LBI) - 13.143/2015 promoveu mecanismos para que os estudantes requeiram subsídios para a permanência, em sua realidade social universitária, que resultou em parâmetros legais que promovessem condições mínimas de acessibilidade criando: "[...] possibilidade e condição de alcance para utilização, com segurança e autonomia, de espaços, mobiliários, equipamentos urbanos, edificações,

\footnotetext{
${ }^{1}$ Será mantido neste texto o termo "pessoa com deficiência" de acordo com o documento adotado pela Convenção sobre os direitos das Pessoas com Deficiência.
} 
transportes, informação e comunicação, inclusive seus sistemas de tecnologias [...] (BRASIL, 2015, p. 1)".

Para Manzini (2006) a acessibilidade deve estar voltada para a participação em atividades, processo de transformação do ambiente, da organização físico-espacial, do atendimento, da administração, das atitudes, do comportamento, bem como da transformação de atividades que diminuam as sequelas de determinadas deficiências.

A acessibilidade tem representado um desafio para a educação superior, pois traçar ações educativas com a participação dos estudantes, nesse contexto, faz parte de um conjunto fundamentado na cidadania e democracia. Na educação superior, a educação inclusiva se efetiva por meio de canais que, aos poucos, têm promovido o acesso e a permanência desse público em espaços acadêmicos.

Estas propostas inclusivas envolvem o planejamento e a organização de recursos e serviços para a garantia da acessibilidade arquitetônica, nas comunicações, nos sistemas de informação, nos materiais didáticos e pedagógicos, que devem ser disponibilizados desde os processos seletivos até o desenvolvimento de todas as atividades que envolvam o ensino, a pesquisa e a extensão (BRASIL, 2008). Seguindo os mesmos parâmetros Mendes (2003) pressupõe que: "A ciência será essencial para que a sociedade brasileira busque contribuir, de maneira intencional e planejada, para a superação de uma educação especial equivocada que atua contra os ideais de inclusão social e plena cidadania (p. 3)".

Sendo assim, o papel da universidade é o de proporcionar espaços inclusivos aos estudantes com "deficiência", conforme definida pela Lei Brasileira de Inclusão -13.143/2015 como: “[...] àqueles que apresentam impedimento a longo prazo de natureza física, mental, intelectual ou sensorial, o qual em interação com uma ou mais barreiras, pode obstruir sua participação plena e efetiva na sociedade em igualdade de condições com as demais pessoas (BRASIL, 2015, p. 1)”. Desse modo é por meio de diversos atores engajados em prol da luta pelos direitos dessa população que este estudo caminhou, visando a necessidade em se desenvolver a referida pesquisa voltada para os problemas da realidade com vistas a conhecer as práticas e políticas transparentes (MENDES, 2003).

Para tanto, revisou-se as principais pesquisas que analisaram níveis de satisfação de estudantes pertencentes ao público geral ou público-alvo da educação inclusiva em IES, a saber. Revisou-se estudo de Polydoro et al. (2001) o qual construiu uma escala de Integração ao Ensino Superior, enfocaram as características psicológicas, compreensão da personalidade, estilos de pensamento, integração acadêmica e relação com a área de formação de estudantes universitários. Participaram 633 universitários, do público geral, provenientes de vários 
cursos de graduação e os resultados apontaram para aderência, satisfação no curso e fatores externos ao ambiente universitário; aspectos internos do indivíduo, de capacidade de enfrentamento, reações físicas psicossomáticas e estado de humor.

Nessa direção, Schleich, Polydoro e Santos (2006) realizaram estudo com 351 estudantes, do público geral, do ensino superior de uma IES, e aplicaram uma Escala de Satisfação de Experiência Acadêmica (ESEA) de Soares, Vasconcelos e Almeida (2002). Avaliaram a satisfação dos estudantes de ensino superior em relação a aspectos ocupacionais no contexto acadêmico e verificaram que o nível de satisfação interfere, fortemente, em seus envolvimentos junto à instituição visto que a satisfação é uma variável psicossocial de mediação e de inclusão acadêmica desse alunado.

Guerreiro (2011) avaliou o nível de satisfação de alunos com deficiência por meio da aplicação da Escala de Satisfação e Atitudes de Pessoas com Deficiência (ESA) construída para este fim. Como resultado pontuou, no item fator estrutural, que $75 \%$ da amostra de estudantes com deficiência tendem à satisfação, enquanto que os outros $25 \%$ demonstraram tendências de insatisfação.

No fator operacional, $50 \%$ encontram-se satisfeitos e $50 \%$ tendem a insatisfação, já no item psicoafetivo, 25\% apresentam satisfação e $75 \%$ estão insatisfeitos. Em relação as atitudes perante os obstáculos, $25 \%$ preferem uma neutralidade ou permanecem omissos; por outro lado $75 \%$ apresentam atitudes positivas. Quanto ao conhecimento da antiga NBR 9050/2004, cerca de $60 \%$ conhecem pouco a norma de acessibilidade, por outro lado $40 \%$ de estudantes com deficiência visual acessavam muito a legislação e consecutivamente apresentaram maior nível de satisfação operacional.

Corrêa (2014) mediu o nível de satisfação e as opiniões de 12 alunos com deficiência em relação a seu acesso e permanência em sete faculdades pesquisadas. Utilizou a Escala de Satisfação e Atitudes de Pessoas com Deficiência (ESA), desenvolvida por Guerreiro (2011). Seu resultado pontuou que a satisfação de alunos com deficiência visual apresentou índice maior quando comparado com estudantes com deficiência física e auditiva.

A pesquisa de Baú (2015) avaliou as condições de acessibilidade da Universidade Tecnológica Federal do Paraná (UTFPR) - Campus Medianeira e mensurou o nível de satisfação quanto a acessibilidade no campus através da aplicação da ESA. Houve pontuações baixas voltadas para necessidade de maiores informações no edital, recursos didáticos na seleção e para as aulas, utensílios na biblioteca e ações atitudinais voltadas para satisfação psicoafetiva. 
Os estudos apresentados, até aqui, demonstraram que tais escalas têm se mostrado úteis para direcionar e organizar categorias de avaliação e opinião dos estudantes, embora as pesquisas de Polydoro et al. (2001) e Schleich, Polydoro e Santos (2006) tiveram como participantes estudantes do público em geral. Por outro lado, as escalas aplicadas com o público-alvo da educação inclusiva ainda denotam amostras pequenas em virtude de poucos estudantes acessarem níveis mais qualificados de ensino, tal como o da pós-graduação strictosensu.

Destarte, o atual estudo indagou: como os estudantes público-alvo da educação inclusiva se sentem com as ações ofertadas em seus ambientes universitários? Quais seus anseios e expectativas antes e depois de acessarem o nível de pós-graduação - stricto-sensu e se apresentam ou não atitudes frente as condições ofertadas pelos IES? E teve como objetivo avaliar os níveis de satisfação, expectativas antes e depois de entrarem na pós-graduação stricto-sensu e verificar as atitudes que os estudantes público-alvo da educação inclusiva têm tido diante do cenário atual vivenciado frente às condições de acessibilidade oferecidas nas IES frequentadas.

\section{Metodologia}

Com enfoque quantitativo e qualitativo este estudo se constituiu pela pesquisa mista, do tipo exploratório, cujo anseio foi proporcionar maior familiaridade com o problema de modo a torná-lo mais explícito (GIL, 1995).

A seleção da amostra ocorreu por meio da participação voluntária dos sujeitos e a coleta de dados por intermédio da técnica de indagação para a aplicação de questionário. As amostras selecionadas fizeram parte de subgrupos de estudantes de Instituições de Ensino Superior Públicas do Estado de São Paulo que congregavam cursos de pós-graduação strictosensu em Educação ou Educação Especial cujos estudantes se autodeclararam, no processo seletivo ou no ato da matrícula como público-alvo da educação inclusiva, como também àqueles que foram indicados pelas coordenadorias e secretarias de pós-graduação. Entrava-se em contato por e-mail e/ou telefônico para explicar a pesquisa e verificar o interesse do aluno em participar da pesquisa. Após o aceite, solicitou-se a assinatura do TCLE - Termo de Consentimento Livre e Esclarecido e iniciou-se a aplicação do questionário o qual ocorreu a distância e presencial conforme indicação dos participantes. O tratamento dos dados passou por análise quantitativa da ESA e foram transformados em gráficos com o auxílio do Excel. Interpretaram-se as respostas dos itens 01, 27, 29, 32, 33, 36 e 41 (Quadro 1). 


\subsection{Local}

O local da coleta de dados foi a Universidade Federal de São Carlos (UFSCar), campus sede. As instituições que representaram os estudantes e, portanto, compuseram a amostra foram: 1) Universidade Federal de São Carlos - (UFSCar); 2) Universidade de São Paulo (USP) - campus São Paulo e Ribeirão Preto; 3) Universidade Estadual de Campinas (UNICAMP), campus sede; 4) Universidade Estadual Paulista - UNESP, câmpus de Araraquara e Bauru, destaca-se que essa última também foi consultado manual (conforme sinalização de estudantes com deficiência indicados por autodeclaração no anuário estatístico ${ }^{2}$ de 2015).

Segundo a Universidade Federal de São Paulo - UNIFESP, por ocasião da pesquisa, não havia disponibilização de banco de dados com a quantificação de matrículas de estudantes Público-alvo da Educação Inclusiva. Quanto a Universidade de São Paulo - USP - campus sede foi informado que não disponibilizavam de banco de dados referente a autodeclararão, além de não contarem com esse público no rol de seus estudantes. Assim sendo, ambas instituições não fizeram parte da amostra que compôs esta pesquisa.

\subsection{Descrição do instrumento}

A Escala de Satisfação e Atitudes de Pessoas com Deficiência (ESA) elaborada por Guerreiro (2011) é composta por três partes sendo que a primeira se refere a: A) Dados gerais de identificação; B) Classificação socioeconômica (conforme critérios da Associação Brasileira de Empresas de Pesquisas - APEB, 2015) e C) Escala de satisfação e atitudes de alunos com deficiência com relação à acessibilidade de modo geral.

Vale considerar que a ESA possui 48 itens, sendo que cada um deles apresenta opções de respostas em níveis de gradação que variam entre 1 a 7, considerando que o item de menor valor indica menos satisfação e o item com maior valor representa maior satisfação. Conforme gradação da escala, os dados foram computados a partir dos escores obtidos, sendo multiplicado pelo número de perguntas respondidas, tanto pelo número mínimo quanto pelo máximo.

Desse modo, de um total de 48 questões contidas na ESA, os estudantes puderam responder uma quantidade mínima de 48 itens (caso escolhessem o nível 1 para todas as suas

\footnotetext{
2 Esse documento é elaborado anualmente pela Universidade Estadual Paulista "Júlio de Mesquita Filho" - UNESP e contempla uma série de informações detalhadas sobre as áreas acadêmicas, administrativa e orçamentária, com livre acesso pela população em geral. 
respostas) e, no máximo 336 (se sua escolha fosse o nível 7 para todas as suas respostas).

Todos os gráficos foram organizados a partir da nota atribuída pelo participante, de acordo com o seu nível de satisfação, em cada item da escala. Destaca-se que as respostas tiveram quatro níveis em percentis tais como: insatisfeito (1); tendendo à insatisfação (2 a 4); tendendo à satisfação (5 a 6) e satisfeito (7). Ainda, reuniram questões que mediram a satisfação acerca das condições no âmbito estrutural, operacional, e psicoafetivo e atitudes frente as barreiras conforme descrito no quadro 1 , a saber.

Quadro 1 - Escala de Satisfação e Atitudes de Pessoas com Deficiência (ESA)

\begin{tabular}{|c|c|c|c|}
\hline Itens & $\begin{array}{l}\text { Indicadores } \\
\text { de } \\
\text { avaliação }\end{array}$ & Conceito & Especificidade dos indicadores de avaliação \\
\hline $1-18$ & Estrutural & $\begin{array}{l}\text { Refere-se as condições } \\
\text { arquitetônicas do câmpus, as } \\
\text { vias de acesso e estruturas dos } \\
\text { prédios. }\end{array}$ & $\begin{array}{l}\text { Analisar como os estudantes transitam de um espaço para } \\
\text { outro dentro do câmpus tais como: ter acesso a salas de } \\
\text { aula, biblioteca, auditórios, restaurante universitário, setor } \\
\text { de reprografias, dentre outros. }\end{array}$ \\
\hline \multirow[t]{4}{*}{ 19-31 } & \multirow[t]{4}{*}{ Operacional } & \multirow{4}{*}{$\begin{array}{l}\text { Refere-se aos indicadores que } \\
\text { se de acessibilidade dos } \\
\text { estudantes quanto aos } \\
\text { recursos disponíveis desde o } \\
\text { processo seletivo, mas } \\
\text { também àqueles que são } \\
\text { disponibilizados a partir da } \\
\text { matrícula. }\end{array}$} & $\begin{array}{l}\text { Analisar a satisfação dos estudantes desde o processo } \\
\text { seletivo. }\end{array}$ \\
\hline & & & $\begin{array}{l}\text { Analisar a satisfação frente a reserva de vagas nos } \\
\text { estacionamentos e estarem adequadas de acordo com as } \\
\text { normas NBR-9050/2015. }\end{array}$ \\
\hline & & & $\begin{array}{l}\text { Analisar a satisfação no que se refere a locomoção dentro } \\
\text { do câmpus (garantira de pisos podotáteis, escadas com } \\
\text { corrimão, rebaixamento de guia das calçadas, placas com } \\
\text { sinalização, placas com indicadoras como o código Braille, } \\
\text { dentre outros). }\end{array}$ \\
\hline & & & $\begin{array}{l}\text { Avaliar a satisfação do desenvolvimento acadêmico por } \\
\text { meio do acesso a recursos (operacionais, pedagógicos, } \\
\text { humanos). }\end{array}$ \\
\hline \multirow[t]{3}{*}{ 32-38 } & \multirow[t]{3}{*}{ Psicoafetivo } & \multirow{3}{*}{$\begin{array}{l}\text { Relaciona-se a } r \text { satisfação } \\
\text { interna do } \\
\text { denominada intrapessoal, mas } \\
\text { também a } \\
\text { denominada externa } \\
\text { envolvendo o sentimento de } \\
\text { estar incluído, o nível de } \\
\text { pertencimento a universidade. }\end{array}$} & $\begin{array}{l}\text { Análise voltada para os tipos de expectativas geradas no } \\
\text { estudante previamente }\end{array}$ \\
\hline & & & $\begin{array}{l}\text { Analisar sentimento gerado quanto a autoconfiança } \\
\text { (intrapessoal) }\end{array}$ \\
\hline & & & $\begin{array}{l}\text { Avaliar o sentimento de inclusão social voltado para os } \\
\text { aspectos institucionais (professores, funcionários e colegas. }\end{array}$ \\
\hline \multirow[t]{3}{*}{$39-48$} & \multirow[t]{3}{*}{$\begin{array}{l}\text { Atitudes } \\
\text { diante dos } \\
\text { obstáculos }\end{array}$} & \multirow[t]{3}{*}{$\begin{array}{l}\text { Refere-se as ações dos } \\
\text { estudantes frente as barreiras } \\
\text { encontradas. }\end{array}$} & $\begin{array}{l}\text { Analisar as barreiras arquitetônicas e urbanísticas como: } \\
\text { (escadas, rampas íngremes, portas, vagas nos } \\
\text { estacionamentos, placas, dentre outros). }\end{array}$ \\
\hline & & & $\begin{array}{l}\text { Avaliar as barreiras atitudinais frente ao preconceito, } \\
\text { diferença (colegas, professores, funcionários). }\end{array}$ \\
\hline & & & $\begin{array}{l}\text { Analisar as barreiras por insuficiência de recursos } \\
\text { pedagógicos, operacionais (computadores, mesas adaptadas, } \\
\text { lupa, material em Braille) e comunicacionais (insuficiência } \\
\text { de tradutores e intérpretes de Libras). }\end{array}$ \\
\hline
\end{tabular}

Fonte: Elaboração própria adaptado de GUERREIRO, E. M. B. R. Avaliação da satisfação do aluno com deficiência no ensino superior: estudo de caso da USFCAR. 2011. 229 f. Tese (Doutorado em Educação Especial) - Universidade Federal de São Carlos - UFSCAR, São Carlos, 2011. 
Quadro 2 - Caracterização dos estudantes na Pós-graduação

\begin{tabular}{|c|c|c|c|c|c|}
\hline Part. $^{3}$ & Curso & IES $^{4}$ & $\begin{array}{l}\text { Ano de } \\
\text { ingresso }\end{array}$ & $\begin{array}{l}\text { Prev. } \\
\text { Término }\end{array}$ & Característica \\
\hline P1-UB & Doutorado em Educação & 4 & 2016 & 2020 & Baixa visão \\
\hline P2-US & Doutorado em Educação Especial & 1 & 2014 & 2018 & Deficiência Física \\
\hline P3-US & Doutorado em Educação Especial & 1 & 2013 & 2017 & Baixa visão \\
\hline P4-US & Mestrado em Educação Especial & 1 & 2016 & 2019 & Surdo \\
\hline P5-US & Doutorado em Educação Especial & 1 & 2014 & 2018 & $\begin{array}{c}\text { Transtorno do Espectro } \\
\text { do Autismo }\end{array}$ \\
\hline P6-UC & Mestrado em Educação & 3 & 2014 & 2017 & Surdo \\
\hline P7-UC & Mestrado em Educação & 3 & 2014 & 2017 & Surdo \\
\hline P8-UC & Doutorado em Educação & 3 & 2014 & 2019 & Surdo \\
\hline P9-UR & Mestrado em Educação & 2 & 2015 & 2017 & Surdo \\
\hline
\end{tabular}

Fonte: Elaboração própria

\section{Resultado}

Do total de 13 estudantes convidados a participarem da pesquisa, nove, de acordo com o quadro 2, concordaram com os critérios para a participação, representando um total de $69 \%$ os que se enquadraram nos critérios e tiveram interesse e disponibilidade em participar. Destaca-se que pertenciam ao $1^{\circ}$ ou $2^{\circ}$ ano do (Mestrado) ou $1^{\circ}, 2^{\circ}, 3^{\circ}, 4^{\circ}$ ano do (Doutorado).

Houve predominância de estudantes do sexo feminino totalizando sete (P1, P3, P4, P6, P7, P8 e P9) e dois (P2 e P5) do sexo masculino. A média de idade entre os participantes girou em torno de 34 anos (com máximo de 46 e o mínimo de 25). Quanto ao pertencimento nas IES, houve representatividade de quatro participantes vinculados a UFSCar os quais aderiram aos critérios da pesquisa dos cinco participantes convidados, representando $80 \%$ de participação. Da UNICAMP participaram três, dos cinco convites enviados, ou seja 60\%; já a representação da USP- campus Ribeirão Preto, houve um convidado e um participante, totalizando (100\%). Da UNESP, câmpus Araraquara e Bauru, respectivamente, convidou-se um estudante, mas não houve retorno e da segunda de dois convidados um aceitou participar, representando $50 \%$.

No tocante ao histórico de escolarização dos participantes, quanto ao início de escolarização no Ensino Fundamental, quatro (P1, P2, P3, P5) estudaram em escolas públicas, três (P4, P6 e P8) em escolas particulares e um (P9) estudou em escola pública para surdos;

\footnotetext{
${ }^{3}$ Os participantes serão identificados com siglas P1, P2 e assim sucessivamente a fim de garantir o anonimato.

4 As Instituições de Ensino Superior (IES) as quais pertencem os estudantes estão identificadas com os números 1. UFSCar; 2. USP - Campus Ribeirão Preto; 3. UNICAMP; 4. UNESP- Campus Bauru.
} 
no Ensino Médio, verificou-se predominância de quatro estudantes (P4, P6, P8 e P9), os quais estudaram em instituições particulares enquanto que quatro (P1, P2, P3, P5) cursaram o Ensino Médio em Instituições Públicas.

Avançando para o ensino superior de Graduação, verificou-se que cinco (P3, P4, P6, P8 e P9) dos participantes estudaram em instituições de ensino superior particular, em contrapartida quatro (P1, P2, P5 e P6) estudaram em instituições de ensino superior público.

Sendo assim, verificou-se que houve maiores chances dos estudantes, que cursaram o ensino de Graduação em IES particular, hoje, estarem estudando em IES públicas. Embora a amostra seja pequena ao revelar os dados os quais perfizeram o recorte das realidades locais desta pesquisa. Alguns dos dados acima refletem o destaque das ações afirmativas que, em certa medida, avançou com as políticas de acesso à Reestruturação e Expansão das Universidades Públicas Federais - REUNI e o Programa Universidade para Todos - PROUNI.

Ao receber a devolutiva dos cinco (P4, P6, P7, P8 e P9) sujeitos surdos ${ }^{5}$, dos sete convidados a participarem da pesquisa, mencionaram desconforto ao ler o nome da Escala de Satisfação e Atitudes de Pessoas com Deficiência (ESA). Desses, dois (P4 e P9) participantes surdos, revelaram, no decorrer do preenchimento da escala, não se sentirem à vontade para participar pois não pertencem a categoria de pessoas com deficiência auditiva, mas, sobretudo, à comunidade surda, entretanto, aceitaram participar mesmo discordando com o referido item da escala. Os outros três (P6, P7 e P8), embora também serem surdos, não verbalizaram sobre concordarem ou não com a nomenclatura de deficiência auditiva definida e conceituada na escala, aceitaram contribuir com o presente estudo. A fim de apresentar a diferença entre a pessoa com deficiência auditiva e o surdo, buscou-se definir a pessoa com deficiência auditiva como àquela que na maioria das vezes, faz uso da oralidade para se comunicar, convive com pessoas ouvintes e também se identifica com elas, usam próteses auditivas para aproveitar o resíduo auditivo, diferentemente da pessoa surda que tem como língua, a Língua Brasileira de Sinais (Libras), além de preferir conviver com outras pessoas surdas que lançam mão da Libras. Essas pessoas lutam por direitos à Libras e não se identificam com a língua oral (GESSER, 2009; SALES et al., 2010).

\footnotetext{
${ }^{5}$ Os surdos ou Surdos com letra maiúscula, como proposto por alguns autores não são pessoas que se consideram pessoas com deficiência, uma vez que a língua de sinais, valoriza sua história, arte e literatura como também propõe uma pedagogia própria na caracterização da educação das crianças surdas.
} 
No que se refere a condição socioeconômica, a estimativa de renda domiciliar mensal para os estratos socioeconômicos cinco dos estudantes (P2, P3, P5, P7 e P9) enquadraram-se na classe econômica no nível D, enquanto que dois na classe C2, sendo (P4 e P8) e os outros dois (P1 e P6) na classe C1, de acordo com os parâmetros da $\mathrm{ABEP}^{6}$ (2015). Mensuraram-se as variáveis que representaram dados categóricos, ou seja, que indicaram características de forma ordenadas. Valeu-se da mediana como medida a fim de descrever o conjunto de dados. No arsenal da análise efetuada, encontrou-se $28 \%$ de "não respostas" ou "não se aplica" às questões, sendo que o maior índice de respostas retornou ao fator estrutural. Vale pontuar que não consideraram as "não respostas", pois calculou-se a mediana para cada item e em seguida agruparam-se as questões por tipo de satisfação a fim de obterem-se a mediana, no geral, ou seja, por tipo de satisfação, conforme indicado na Figura 1.

Figura 1 - Níveis de satisfações de acordo com indicadores de avaliação.

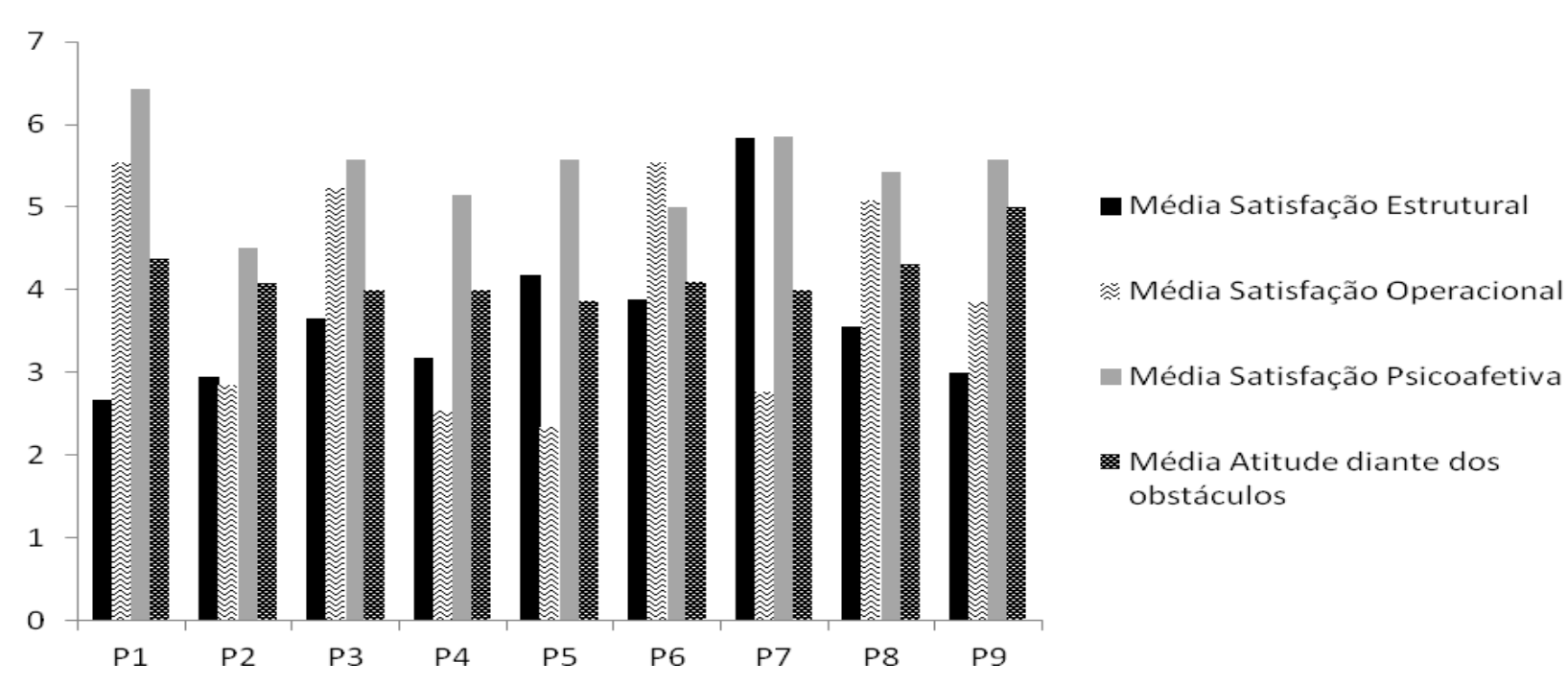

Fonte: A autora

Em seguida, quanto ao Conhecimento da Legislação sobre Acessibilidade, especificamente sobre a NBR 9050/15, grande parte dos estudantes encontram-se politizados e, portanto, vêm discutindo ações e aplicações das legislações em seus cotidianos a fim de pleitearem direitos acerca de suas promoções acadêmicas.

Diante da análise pontuada a respeito do referido item, verificou-se que quatro estudantes (P2, P3, P8 e P9) responderam que conhecem muito sobre a legislação supracitada; 
um (P5) mencionou que conhece, embora não tenha assinalado sobre as gradações (muito ou pouco); outros três (P4, P6 e P7) revelaram conhecerem pouco sobre as legislações disponíveis e um deles (P1) respondeu que não conhece.

Atualmente a NBR 9050/15 apresenta a acessibilidade e a define como:

[...] possibilidade e condição de alcance, percepção e entendimento para utilização, com segurança e autonomia, de espaços, mobiliários, equipamentos urbanos, edificações, transportes, informação e comunicação, inclusive seus sistemas e tecnologias, bem como outros serviços e instalações abertos ao público, de uso público ou privado de uso coletivo [...] (ABNT NBR 9050, 2015, p. 2).

Frente a definição de acessibilidade trazida pela NBR 9050/15, quatro participantes (P2, P3, P5 e P7) assinalaram que a conhecem, por outro lado, outros quatro (P1, P4, P6 e P8) retrataram não conhecerem a norma. E, por último, um (P9) não responderam o quesito. Verificou-se que a maioria dos participantes que não conhecem a NBR 9050 não apresentam necessidades físicas, mas sim de outra natureza, como os surdos e o estudante Transtorno do Espectro do Autismo ${ }^{7}$.

No entanto, verificou-se que com fins de benefícios próprios, apenas os estudantes com necessidade física e visual acessaram, em grande medida, a legislação vigente.

\subsection{Satisfação estrutural}

Conforme o nível de satisfação estrutural, a Figura 1. indicou que oito participantes (P1, P2, P3, P4, P5, P6 P8 e P9) tendem a insatisfação e um participante (P7) tendeu à satisfação, no geral, nos itens de (01 a 18) da escala que se reportam ao: percurso até os prédios acadêmicos, vias de acesso, escadas, rampas, rebaixamento de calçadas, portas e espaços das salas de aula, banheiro, caminho a biblioteca, refeitórios, dentre outros por não estarem nas conformidades para o pleno uso dos estudantes, de acordo com suas necessidades.

No item 01 da escala que se refere ao "Caminho até minha sala de aula é" destaca-se que o estudante que sinalizou tendência a satisfação com as condições físicas dos câmpus não dependia da acessibilidade arquitetônica, ou seja, era um dos estudantes Surdos (P7), os

\footnotetext{
${ }^{7}$ O Transtorno do Espectro Autista (TEA) é definido clinicamente como um transtorno que afeta a comunicação e a interação social, de modo a apresentar déficits na comunicação verbal e não verbal, bem como a ausência de reciprocidade social e dificuldades para manter as relações apropriadas ao seu nível de desenvolvimento. Apresenta padrões restritivos e repetitivos de comportamentos motores e/ou verbais de modo estereotipados, ou também comportamentos sensoriais incomuns, alta fixação em rotinas e padrões de comportamentos que pressupõem interesses restritos, recorte baseado na política nacional de proteção dos direitos da pessoa com TEA.
} 
outros Surdos embora não fossem impedidos pelas barreiras arquitetônicas se sensibilizaram com as barreiras encontradas enfrentadas pelos colegas em seus câmpus acadêmicos.

Quanto ao caminho percorrido até as suas salas de aulas, dos nove participantes, três deles (P4, P5 e P9) consideraram sentirem-se plenamente satisfeito em virtude de não encontrarem barreiras arquitetônicas por serem Surdos ou Transtorno do Espectro do Autismo (TEA). Seguidos de cinco participantes (P1, P2, P3, P6 e P7) que atribuíram nota 4, ao apresentaram tendência a insatisfação desse caminho. Um participante (P8), por outro lado, apresenta tendências a satisfação.

Para o participante cadeirante (P2), este caminho se encontrava com vários obstáculos, assim como para as participantes (P1 e P3), que apresentam baixa visão, o caminho continha barreiras as quais, muitas vezes, impediam-lhes de se locomoverem pelas vias de acesso aos prédios do câmpus universitário. Um participante (P1) mencionou que o campus é pouco iluminado durante a noite e possui calçadas irregulares.

Diante das pesquisas de Melo (2009), Barbosa e Gonçalves (2012), Castro (2011), Guerreiro (2011), Chahini (2013), outros estudantes possuíam dificuldades com as condições arquitetônicas em suas IES e, tais fatores ocorreram devido a estrutura dos prédios ser antiga, cujas construções se remetem a épocas em que não existiam matrículas de estudantes públicoalvo da educação inclusiva nesses espaços e, sobretudo, pela dificuldade da gestão discutir sobre Acessibilidade e Desenho Universal ${ }^{8}$.

\subsection{Satisfação Operacional}

Na satisfação operacional, quatro participantes (P1, P3, P6 e P8) revelaram tendência a satisfação, seguidos de cinco $(\mathrm{P} 2, \mathrm{P} 4, \mathrm{P} 5, \quad \mathrm{P} 7$ e $\mathrm{P} 9)$ que reportaram a tendências à insatisfações, no geral, nos itens da escala (19-31) com as condições que se referem a: garantia de indicações de informações em editais para o público-alvo da educação inclusiva; pisos podotáteis, placas indicando sinalizações, código Braille, materiais para acompanhar as aulas durante o processo seletivo, recursos didáticos, instrutores, ledores e tradutores e intérpretes de Libras durante as aulas, nos eventos e consecutivamente em congressos.

No que tange ao item 27 da escala "Existência de recursos humanos na biblioteca", o participante surdo (P9) avaliou como ineficiente, pois considerou não ter profissional de

\footnotetext{
${ }^{8}$ De acordo com a Lei Brasileira de Inclusão - "Desenho universal" a concepção de produtos, ambientes, programas e serviços a serem usados por todas as pessoas, sem necessidade de adaptação ou de projeto específico, incluindo os recursos de Tecnologia Assistiva.
} 
intérprete de Libras na biblioteca para dar maiores informações. Sequencialmente, os participantes surdos (P6 e P7) e (P1) com baixa visão apresentaram tendência a ineficiência pois consideraram insuficiência de profissionais quando precisam do serviço da biblioteca, como o ledor, por exemplo.

Por outro lado, (P4 e P8), participantes surdos, vislumbraram tendências à satisfação, no que se refere a disponibilidade do profissional no campus. Consideraram que quando solicitam auxílio são prontamente atendidos em suas necessidades.

E, por fim, três participantes (P2, P3 e P5) assinalaram que o referido item não se aplica a eles, considerados os estudantes com deficiência física, um com baixa visão e o TEA, respectivamente. Embora a (P3) ter assinalado que este item não se aplica a ela, mencionou verbalmente que todas as vezes que precisa de um profissional que escaneie livros, não conta com esse auxílio.

Diante da barreira encontrada pela participante (P3), estabelece interface com o estudo sobre mobilidade e comunicação desenvolvido por Lopes e Burjato (2010) ressaltando a necessidade de as IES romperem com os obstáculos que denotam conexão com a orientação e conceitos espaciais, pois visualizaram presença de: sensações de isolamento, desconforto sobre o posicionamento e uso dos equipamentos e objetos, insegurança, incompreensão e dimensionamento dos espaços.

Os autores Cruz e Bizelli (2014) pontuam que o cenário digital é necessário para a utilização das Tecnologias de Informação e Comunicação (TICs) uma vez que estão cada vez mais avançadas e alertaram para que haja Formação Profissional Inicial voltada para educação nos meios digitais. A utilização das TICs, no contexto universitário, pode ser concebida como um facilitador para a remoção de barreiras metodológicas e comunicacionais.

No que tange ao item 29 da escala "Meu êxito acadêmico depende da acessibilidade física aos ambientes" indo da gradação de total para parcial, recebeu diversas formas de análise. O participante (P2), o qual apresenta deficiência física, revelou que seu êxito depende totalmente de sua acessibilidade física e seu sucesso acadêmico. Já os participantes (P1e P3), os quais apresentam baixa visão, retrataram que seus êxitos acadêmicos dependem, em grande medida, da acessibilidade arquitetônica nos ambientes universitários. Os participantes $(\mathrm{P} 4 \mathrm{e}$ P8), surdos, assinalaram nota 5, os quais dependem parcialmente da acessibilidade física, considerando a acessibilidade (comunicacional), ao invés da física, para que tenham eficácia acadêmica.

Embora seja surdo, o participante (P9) indicou sentir-se incomodado e assinalou o item 7, cuja resposta indica parcialidade, destacando que não carece de acessibilidade física, 
mas sim de acessibilidade na comunicação, respondendo conforme a sua necessidade, o que configurou que seu êxito depende parcialmente da acessibilidade comunicacional no campus. Um estudante com baixa visão e um surdo (P3 e P6) atribuíram nota 7, indicando parcialidade em relação ao seu êxito estar relacionado com a acessibilidade física do campus.

Com vistas às dificuldades encontradas pelos estudantes, destaca-se o princípio do Desenho Universal (Cartilha de Acessibilidade para Web - Fascículo I) compreendido como o desenvolvimento de produtos e ambientes, uma vez que leva em conta todas as diferenças pessoais, sem a necessidade de adaptação. Constitui-se a partir da visão de mundo projetada para atender, da melhor forma possível, todas as pessoas, ao invés de exigir-lhes esforços de adaptação (BRASIL, 2013).

\subsection{Satisfação Psicoafetiva}

A satisfação psicoafetiva refere-se as condições voltadas às expectativas que os estudantes tinham antes e depois de entrarem no curso superior de pós-graduação. Como também, os sentimentos dos estudantes em transitar pelo campus, o grau de envolvimento com o curso, o envolvimento interpessoal, o sentimento de autoestima, o de autovalorização. Portanto, sentir-se incluído pela Instituição, envolveu aspectos de apoios por parte dos professores e colegas para com a efetiva inclusão dos estudantes nos cursos de ensino superior de Pós-graduação Stricto-sensu.

Os níveis de satisfação psicoafetiva dos sujeitos indicaram que oito estudantes (P1, P3, P4, P5, P6, P7, P8 e P9) possuíram tendência a satisfação, enquanto que um apresentou tendências a insatisfação (P2) nos aspectos gerais dos itens (32-38) da escala sobre os fatores psicoafetivos.

Quanto ao item 32, sobre as "Expectativas antes de entrar na instituição" verificou-se que três participantes (P1, P8 e P9) apresentaram tendências negativas, enquanto que quatro participantes apresentaram tendências positivas (P2, P4, P6 e P7) e dois (P3 e P5) apresentaram positividade.

No que se refere ao item 33 - "Expectativas depois de entrar na instituiçãoo", três participantes (P1, P2 e P5) indicaram tendência a negatividade; quatro (P4, P6, P7 e P9) apresentaram características crescentes que denotam positividade e, por fim, encontraram-se positivos os estudantes P3 e P8.

Em específico, verificou-se que (P1, P2 e P5) tinham expectativas positivas antes de entrarem nas IES, porém diminuíram quando começaram a participar e se envolverem com as 
atribuições acadêmicas. Pontuaram que as expectativas baixaram pois se depararam com o despreparo de alguns funcionários para lidar com questões relacionadas à deficiência visual, deficiência física e com as especificidades do aluno com TEA. Em contrapartida, os estudantes (P4, P6, P8 e P9) aumentaram suas expectativas ao entrar no mundo acadêmico, pois acreditaram que as Unidades Universitárias estão melhorando a cada ano. E dois participantes (P3 e P7), com baixa visão e surdez, mantiveram a mesma pontuação atribuída antes e depois de entrarem nas Universidades.

Em específico, o participante (P3), com baixa visão, demonstrou ter expectativa positiva antes e depois de entrar no curso de Pós-graduação. Embora não tenha oscilado entre as expectativas entre antes e depois, apreciou a qualidade da universidade ter muita qualidade e profissionais de ponta. O sujeito (P2), com deficiência física, apresentou expectativa como fator positivo antes de ingressar no curso de pós-graduação, pois acreditou que encontraria um ambiente totalmente acessível por meio de uma acessibilidade arquitetônica e, sobretudo, atitudinal, que, por sua vez, atendessem as necessidades e potencialidade de todos. Todavia, diminuiu suas expectativas ao entrar no curso ao se deparar com lacunas no que se refere a barreira física e atitudinal que, por sua vez, poderiam ser evitadas com um planejamento concreto e consciente, com vistas a inclusão das pessoas público-alvo da educação inclusiva, na graduação e na pós-graduação.

Glat (1995) coaduna com o exposto acima uma vez que, a inclusão de estudantes público-alvo da educação inclusiva, não pode ser vista, tão somente, por um prisma de falta de políticas públicas, mas sobretudo, pela insuficiência de recursos humanos especializados o que dificulta o acesso e a permanência de estudantes em níveis mais qualificados de ensino.

Manzini (2008) também considera relevante a necessidade de qualificação profissional para a utilização de recursos de informática, mas também os providos pelas Tecnologia Assistiva $^{9}$, pois existe desconhecimento por parte de profissionais como também de programas; construções de equipamentos e materiais didáticos a serem utilizados junto aos alunos público-alvo da educação inclusiva.

Para romper com as barreiras atitudinais encontradas pelos estudantes em suas IES, Omote (1999) define o desvio e o estigma como fatores de natureza psicossocial e cultural que surgem a partir das relações interpessoais. Ainda, quando criado o "[...] desvio, são

\footnotetext{
9 O recurso de Tecnologia Assistiva deve ser compreendido por produtos, equipamentos, dispositivos, metodologias, estratégias, práticas e serviços que indicam a funcionalidade, relacionada à atividade e à participação da pessoa com deficiência ou com mobilidade reduzida, buscando sua autonomia, independência, qualidade de vida, bem como a sua inclusão social.
} 
identificadas as pessoas que podem ser colocadas na respectiva categoria de desviante e são criados tratamentos distintivos destinados a essas pessoas (p. 10)".

Nuernberg (2009) conceitua barreiras atitudinais como àquelas encontradas, pelos estudantes, no âmbito acadêmico e considera que são os estereótipos, bem como os preconceitos, opressões e cerceamentos sofridos pelos estudantes, público-alvo da educação inclusiva. Por meio dessa definição, os níveis de satisfação psicoafetivas e as atitudes perante os obstáculos estão estritamente ligados às barreiras atitudinais vivenciadas. Pois acreditar-se que os estudantes necessitam de espaço para verbalizarem seus sentimentos, angústias e frustrações vivenciadas nos contextos acadêmicos, bem como devem ser orientados a romperem com tais barreiras que não possibilitam sua ascensão e, consequentemente, seus sucessos acadêmicos.

A fim de ilustrar as expectativas positivas e negativas, o participante (P5), participante com TEA, teve perspectiva positiva após ser inserido no curso de ensino superior de Pósgraduação e diminuiu, acentuadamente, no decorrer do curso. Os entrevistados surdos (P4, P6, P8 e P9) tiveram menos expectativas antes de entrar no Mestrado ou Doutorado e se surpreenderam no percurso. O participante (P4) mencionou que antes de entrar na Pósgraduação preocupava-se em ter acesso a um intérprete nos dois anos de vigência do curso, o que seria uma monotonia, por não ter colegas sinalizantes em seu curso para se comunicar naturalmente. Contudo, a expectativa foi superada e, portanto, tornou-se positiva quando a universidade disponibilizou quatro intérpretes de Libras, o que amenizou sua preocupação com a monotonia entre a estudante surda e o intérprete de Libras e da possível relação que teria apenas com um intérprete, ao longo de sua trajetória acadêmica. Houve novas superações quanto ao revezamento dos intérpretes o que proporcionou melhor relação com os ouvintes e com os professores universitários. Ainda, demonstrou alívio uma vez que seus colegas sinalizantes facilitam sua autonomia em comunicar-se ao discutirem sobre o mundo acadêmico sem a total dependência dos intérpretes.

O item 36 que se referiu ao "Sentimento de inclusão nas Instituições de Ensino Superior", suas respostas oscilaram entre as notas três e seis cujas variações da escala giram em torno de 0 a 7 , em que 1 se refere a parcial e 7 no total.

Os participantes (P1, P3 e P7) indicaram tendência a insatisfação, pois não se sentiram incluídos em suas IES. Vale destacar que a participante (P3) pontuou a nota três e considerou que quase não existe adaptação, sentia-se desmotivada por necessitar digitalizar vários materiais, e alguns professores traduzem os slides nas aulas, mas outros não. Referiu-se a dificuldade na descrição das apresentações de seus trabalhos orais pelos próprios colegas ao 
apresentarem suas pesquisas. Os participantes (P2, P4, P5, P6, P8 e P9) avaliaram suas inclusões pontuaram notas crescentes no tocante a sentimentos recíprocos nas universidades.

\subsection{Atitude diante dos obstáculos}

Por conseguinte, ao medir o nível de satisfação dos estudantes perante as atitudes e obstáculos, inferiram-se sobre as reivindicações de seus direitos, pela busca do exercício de sua autonomia; ações permeadas pelos conhecimentos, acessos e aplicações das legislações disponíveis a fim de favorecerem seus plenos acessos aos saberes qualificados. No que concerne as atitudes junto a população investigada, os itens gerais do 39-48, oito participantes (P1, P2, P3, P4, P5, P6, P7 e P8) aproximaram-se de tendências à insatisfação, e um (P9) se voltou para a insatisfação diante das dificuldades e barreiras que se depararam, no geral.

No que se refere ao item 41 sobre "Considero acionar o Ministério Público quando minhas necessidades, quanto acessibilidade física ou de comunicação não são atendidas", desde nunca até sempre, constatou-se que dos nove participantes entrevistados, três (P1, P5 e P8) indicaram valor 1 para a questão, pois não acionam o órgão competente quando seus diretos são violados. Entretanto, três participantes, um com baixa visão e outros dois surdos (P3, P4 e P6) assinalaram valor 7, ou seja, já acionaram o Ministério Público, enquanto que os demais (P2 e P7) indicaram valor entre 2 e 4, indicando que quase nunca aciona. E ainda, um participante (P9) apresentou tendências a acionar o MP para garantir seus direitos de comunicação, quando não são atendidos.

Os resultados deste item indicaram que metade dos estudantes nunca acionaram o MP, enquanto que outros dois estudantes indicaram não necessidade em acionar e a outra metade já moveram ações para garantirem sua acessibilidade nos câmpus. Desse modo, uma minoria encontra-se empoderado para solicitarem ações em prol de seu pleno desenvolvimento acadêmico, o que vai de encontro com os preceitos de Manzini (2008) a respeito das IES proverem Leis específicas na área da acessibilidade para pessoas com deficiência, o que poderia despertar nos estudantes motivações para reivindicarem ações para a universidade, uma vez já previstos os auxílios e recursos tecnológicos e/ou material didático, não se sentiriam culpados.

Contudo, o fator das políticas públicas, no Ensino Superior, não prevê a operacionalização, por meio de Leis, Decretos e Resoluções, nem mesmo a garantia da permanência e a conclusão dos estudantes, haja vista a carência de recursos e demais 
materiais voltados a essa população para que, de fato, possam usufruir da acessibilidade em seus câmpus acadêmicos.

Por fim, vale destacar a Portaria Normativa no 13/2016 (BRASIL, 2016), instituída pelo MEC, pressupõe às ações afirmativas na Pós-Graduação Stricto-sensu considerando que as IES deverão perfazer a reserva de $20 \%$ de vagas para pessoas negras, indígenas e com deficiência. Tendo em vista propagar o número de matrículas dessas populações em níveis de ensino mais qualificados.

De repente, com essa normativa e demais instrumentos legais, aumentam-se o número de matrículas, nos cursos superiores de Pós-graduação stricto-sensu, bem como as ações em busca de melhorias, nos espaços universitários; ênfase em proporcionar, com maior frequência, a cultura de espaços mais acolhedores, acessíveis e adaptados as suas necessidades, em detrimento de ações individuais que se responsabilizem por impetrarem ações em favor de suas acessibilidades.

\section{Conclusão}

A aplicação da ESA, nesta pesquisa, permitiu conhecer os níveis de satisfações encontrados por nove estudantes público-alvo da educação inclusiva inseridos em níveis de educação superior de pós-graduação stricto-sensu de quatro instituições de ensino superior público que dispunham de cursos de Mestrado e/ou Doutorado em Educação e Educação Especial.

Diante do arsenal apresentado, perceberam-se ações pontuais que garantiram níveis de satisfações desses estudantes em espaços acadêmicos em quatro segmentos investigados, sendo eles: satisfação estrutural, satisfação operacional, satisfação psicoafetiva e satisfação frente aos obstáculos.

Os níveis de satisfações verbalizados pelos estudantes enfatizaram suas principais dificuldades diante das barreiras encontradas. Por outro lado, visualizou-se um panorama atual das unidades universitárias pesquisadas, possibilitando a identificação de um conjunto de ações satisfatórias voltadas para a permanência do estudante, mas também àquelas que ainda são barreiras impeditivas para a efetiva permanência no ambiente universitário. Em síntese, os itens de satisfação, nos itens específicos, de acordo com a gradação da escala, indicados pelos estudantes no ambiente universitário, referiram-se a:

$\checkmark$ Muita satisfação: Estrutural: apenas três participantes (P4 e P5 e P9) encontram-se completamente satisfeitos no item referente ao caminho percorrido até suas salas de aulas. Operacional: nenhum estudante se encontra completamente satisfeito no que 
tange a existência de recursos humanos na biblioteca. E quanto a sentir-se incluído nas IES, não houveram respostas que se reportassem para total inclusão.

$\checkmark$ Tendência à Satisfação: Estrutural: um participante (P8) tendeu para a satisfação a respeito do caminho até sua sala de aula; Operacional: quanto a existência de recursos humanos na biblioteca apenas um estudante (P8) pontuou valor 6, indicando fator promissor para este quesito. Psicoafetivo: no que se refere a sentir-se incluído nas IES, seis estudantes (P2, P4, P5, P6, P8 e P9) estão sendo acolhidos, aceitos e respeitados em suas diferenças.

$\checkmark$ Tendência à Insatisfação: Estrutural: cinco participantes (P1, P2, P3, P6, P7) sinalizaram fatores de risco no contexto estrutural, envolvendo notas mais baixas, não favoráveis ao percurso até suas salas de aula; Operacional: no tocante a existência de recursos humanos na biblioteca, quatro estudantes tendenciam para insatisfação (P1, P6, P7 e P9). Psicoafetivo: quanto a sentirem-se incluído nas IES, (P1, P3 e P7) ainda não sentem que suas relações interpessoais, nos câmpus, estão satisfatórias, ainda se reportam a presença de preconceitos e, por vezes, invisibilidades, nos espaços universitários, nos quais pertencem.

$\checkmark$ Insatisfação: Estrutural: dentre os itens analisados não houveram índices de total insatisfação; Operacional: um estudante (P9) revelou apresentar insatisfação total no que concerne a existência de recursos humanos para atendimento na biblioteca. Psicoafetivo: quanto aos itens investigados também não se encontrou índices de insatisfação total neste fator.

Ante o exposto, percebeu-se que as Instituições de Ensino Superior vêm promovendo alguns fatores que facilitam a permanência dos estudantes público-alvo da educação inclusiva na universidade, mas, por outro lado, ainda existe um cenário de dificuldades em contemplar ações que garantam espaços inclusivos.

Mediante os dados analisados pôde-se identificar a influência, a inclusão dos estudante público-alvo da educação inclusiva no ensino superior de pós-graduação, como o currículo, necessidades de recursos utilizados, as condições dos espaços arquitetônicos, as barreiras atitudinais, assim como a satisfação e insatisfação encontradas pelos estudantes nesse processo. Para tanto, a responsabilidade em oferecer as adaptações específicas aos estudantes são das próprias IES para que, de fato, correspondam com as expectativas positivas de seu corpo de alunado (POLYDORO et al., 2001).

Observou-se no conteúdo das respostas e falas dos participantes anseios para que as Universidades possam prover modificações estruturais, no tocante às mudanças de projetos universitários e, de forma preponderante, aspectos de mudanças socioculturais, de sorte a intensificarem a luta pelos direitos do público-alvo da educação inclusiva, dentro do contexto acadêmico. Os achados demonstraram que mesmo em pequena medida, vale focar em debates para a remoção de preconceitos que ainda são identificados pelos estudantes no campo acadêmico, caracterizado pela barreira atitudinal. 
Consecutivamente, um dado significativo, voltou-se para a importância de apoios no âmbito metodológico, uma vez que cabe ao próprio estudante, na maior parte das vezes, criar condições individuais para se adaptar a métodos empregados na sala de aula.

Um dado que merece destaque é que, talvez, os documentos oficiais disponibilizados pelas IES não revelem dados correspondente com a realidade, pois existem dificuldades no mapeamento desses estudantes, em vista de duas IES terem ficado de fora deste estudo por não disporem de documentos internos que propiciem o levantamento dessas informações.

A Escala de Satisfação e Atitudes de estudantes com deficiência - ESA está em processo de validação, então seria interessante observar alguns itens do questionário os quais necessitam ser revistos como o título da escala; no quesito que se refere aos dados gerais na parte A, rever os tipos de deficiências inseridos; rever os recursos utilizados para deslocamento ou comunicação; atualizar os itens da classificação socioeconômica; revisar os itens da própria escala de satisfação e atitudes, observando os resultados encontrados na aplicação da mesma.

Um item que merece destaque se refere às reivindicações dos estudantes surdos que fizeram questão de diferenciarem das pessoas com deficiências auditivas corroborando com Bisol e Valentini, (2011, p. 1-2) como: [...] àquelas que não se identificam com a cultura e a comunidade surda, já [...] o surdo que se identifica com a língua de sinais e a comunidade surda não gosta de ser chamado de deficiente auditivo. Ele tem orgulho de ser surdo e não se considera uma pessoa com deficiência.

Enfim, os resultados indicados neste estudo puderam auxiliar e elevar o entendimento do impacto nos níveis de satisfações dos estudantes público-alvo da educação inclusiva quanto a diversidade e expectativas geradas antes e depois de cursarem pós-graduação strictosensu e, sobretudo, conclui-se que a invisibilidade das ações oferecidas pelas instituições podem gerar falhas nos cursos superiores de pós-graduação stricto-sensu. Para tanto, devem estar atentas e ofertarem espaços que alavanquem o ensino de qualidade junto ao seu corpo de estudantes.

\section{Referências}

ASSOCIAÇÃO BRASILEIRA DE NORMAS TÉCNICAS. NBR 9050: acessibilidade a edificações, mobiliário, espaços e equipamentos urbanos. Rio de Janeiro: ABNT, 2015. Disponível em: http://www.ufpb.br/cia/contents/manuais/abnt-nbr9050-edicao-2015.pdf. Acesso em: 2 nov. 2016. 
ASSOCIAÇÃO BRASILEIRA DE EMPRESAS DE PESQUISA - ABEP. Classificação socioeconômica do critério de classificação econômica Brasil, 2015. Disponível em: file://C:/Users/user/Downloads/01_cceb_2015\%20(1).pdf. Acesso em: 21 nov. 2016.

BARBOSA, M. M.; GONÇALVES, A. G. Acesso e permanência do aluno com deficiência no Ensino Superior: um estudo de caso na Universidade Federal do Tocantins, campus de Miracema. In: JORNADA DE EDUCAÇÃO ESPECIAL, 11, 2012, Marília. Anais[...] Marília: Oficina Universitária, 2012. 1 CD.

BAÚ, M. A. Avaliação da acessibilidade no ensino superior: UTFPR - Campus Medianeira. 2015. 123 f. Dissertação (Mestrado) - Faculdade de Filosofia e Ciências, Universidade Estadual Paulista Júlio de Mesquita Filho, Marília, 2015. Disponível em: http://hdl.handle.net/11449/123889. Acesso em: 12 maio 2016.

BISOL, C. A.; VALENTINI, C. B. Surdez e deficiência auditiva - qual a diferença? Objeto de aprendizagem Incluir - UCS/FAPERGS, 2011. Disponível em: http://www.grupoelri.com.br/Incluir/downloads/OA_SURDEZ_Surdez_X_Def_Audit_Texto. pdf. Acesso em: 20 nov. 2016.

BRASIL. Aviso Circular no 277 de 08 de maio de 1996. Brasília, 1996. Disponível em: http://portal.mec.gov.br/seesp/arquivos/pdf/aviso277.pdf. Acesso em: 1 jan. 2017.

BRASIL. Presidência da República. Lei no . 10.098, de 19 de dezembro de 2000. Brasília, 2000. Disponível em: http://www.planalto.gov.br/ccivil_03/leis/L10098.htm. Acesso em: 3 maio 2016.

BRASIL. Ministério da Educação. Portaria no 3.284, de 7 de novembro de 2003. Brasília, 2003. Disponível em: http://portal.mec.gov.br/seesp/arquivos/pdf/port3284.pdf. Acesso em: 2 jan. 2016.

BRASIL. Ministério da Educação/Secretaria de Educação Especial. Política Nacional de Educação Especial na perspectiva da Educação Inclusiva. Brasília, 2008.

BRASIL. Ministério da Educação. Lei no. 12.764, de 27 de dezembro de 2012.Institui a Política Nacional de Proteção dos direitos da Pessoa com Transtorno do Espectro Autista. Brasília, 2012.

BRASIL. Cartilha de Acessibilidade para Web. Fascículo I. Brasília, 2013. Disponível em: http://www.w3c.br/pub/Materiais/PublicacoesW3C/cartilha-w3cbr-acessibilidadewebfasciculo-I.html. Acesso em: 21 nov. 2016.

BRASIL. Ministério da Educação. Lei no 13.146, de 06 de julho de 2015. Lei Brasileira de Inclusão - Estatuto da pessoa com deficiência. Brasília, 2015.

BRASIL. Ministério da Educação. Portaria Normativa nº 13, de 11 de Maio 2016. Dispõe sobre a indução de Ações Afirmativas na Pós-Graduação, e dá outras providências. Diário oficial da República Federativa do Brasil, Brasília, DF, 12 maio 2016.

CASTRO, S. F. Ingresso e permanência de alunos com deficiência em universidades públicas brasileiras. 2011. 278f. Tese (Doutorado em Educação Especial) - Universidade Federal de São Carlos, São Carlos, 2011. Disponível em: https://repositorio.ufscar.br/bitstream/handle/ufscar/2878/3611.pdf? sequence=1\&isAllowed= y. Acesso em: 28 de mar. 2016.

CHAHINI, T. H. C. Inclusão de alunos com deficiência na educação superior. Curitiba: Instituto Memória, 2013. 
CORRÊA, P. M. Acessibilidade no ensino superior: instrumento para avaliação, satisfação dos alunos com deficiência e percepção de coordenadores de cursos. 2014. $281 \mathrm{f}$. Tese (Doutorado) - Faculdade de Filosofia e Ciências, Universidade Estadual Paulista, Marília, 2014.

CRUZ, J. A. S.; BIZELLI, J. L. Ensino Superior e a formação de docentes: educar para os meios a partir da pós-graduação lato sensu. In: INTERCOM - SOCIEDADE BRASILEIRA DE ESTUDOS INTERDISCIPLINARES DA COMUNICAÇÃO, 5, 2014, Foz do Iguaçu/PR. Anais[...] Foz do Iguaçu, 2014. p. 1-14. Disponível em: http://www.intercom.org.br/papers/nacionais/2014/resumos/R9-0111-1.pdf. Acesso em: 22 nov. 2016.

GESSER, A. LIBRAS? Que língua é essa? Crenças e preconceitos em torno da língua de sinais e da realidade surda. São Paulo: Parábola Editorial, 2009.

GLAT, R. A integração social dos portadores de deficiência: uma reflexão. Rio de Janeiro: Sette Letras, 1995.

GIL, A. C. Como elaborar projetos de pesquisa. 3. ed. São Paulo: Atlas, 1995.

GUERREIRO, E. M. B. R. Avaliação da satisfação do aluno com deficiência no ensino superior: estudo de caso da USFCAR. 2011. 229 f. Tese (Doutorado em Educação Especial) - Universidade Federal de São Carlos - UFSCAR, São Carlos, 2011.

LOPES, M. E.; BURJATO, A. L. P. F. Ergonomia e acessibilidade. In: ORNSTEIN, S. W.; ALMEIDA PRADO, A. R.; LOPES, M. E. Desenho universal: caminhos da acessibilidade no Brasil. São Paulo: Annablume, 2010.

MANZINI. E. J. (org.). Inclusão e acessibilidade. Marília: ABPEE, 2006.

MANZINI. E. J. Acessibilidade: um aporte na legislação para o aprofundamento do tema na área de educação. In: BATISTA, C. R.; CAIADO, K. R. M; JESUS, D. M. de (org.). Educação especial: diálogo e pluralidade. Porto Alegre: Mediação, 2008. p. 281-289.

MELO, F. R. L. V. Mapeando, conhecendo e identificando ações da Universidade Federal do Rio Grande do Norte diante do ingresso de estudantes com deficiência. In: MARTINS, L. A. R. et al. (orgs.). Práticas inclusivas nos sistemas de ensino e em outros contextos. Natal: EDUFRN, 2009. p. 81-109.

MENDES, E. G. A. educação inclusiva e a universidade brasileira. Espaço (INES), Rio de Janeiro, v. 18, n. 19, p. 42-44, 2003. Disponível em:

$<$ http://www.educacaopublica.rj.gov.br/biblioteca/educacao/0065.html. Acesso em: 3 abr. 2014.

NUERNBERG, A. H. A Psicologia no contexto da educação inclusiva: rompendo barreiras atitudinais no contexto do ensino superior. In: ANACHE, A. A.; SILVA, I. R. da. (orgs.) Educação inclusiva: experiências profissionais em psicologia. Brasília: Conselho Federal de Psicologia, 2009. p. 153-166.

OMOTE, S. Deficiência: da diferença ao desvio. In: MANZINI, E. J.; BRANCATTI, P. R. (org.). Educação especial e estigma: corporeidade, sexualidade e expressão artística. Marília: UNESP-Marília-Publicações, 1999. p. 3-21.

POLYDORO, S. A. J. et al. Desenvolvimento de uma escala de integração ao ensino superior. Psico USF, São Paulo, v. 6, n. 1, p. 11-17, 2001.

SALES, A. M. et al. Construindo conhecimento sobre a surdez Língua Brasileira de Sinais Libras (LIBRAS) e educação de surdos. Caderno-UFSCar, São Carlos, 2010. 
SCHLEICH, A. L. R.; POLYDORO, S.; SANTOS, A. A. A. dos. Escala de satisfação com a experiência acadêmica de estudantes do ensino superior. Avaliação Psicológica:

Interamerican Journal of Psychological Assessment, Porto Alegre, v. 5, n. 1, p. 11-20, 2006.

SOARES, A. P. C.; VASCONCELOS, R. M.; ALMEIDA, L. S. Adaptação e satisfação na universidade: apresentação e validação do questionário de satisfação acadêmica. Contextos e dinâmica da vida acadêmica. Guimarães, Portugal: Universidade do Minho, 2002.

UNIVERSIDADE ESTADUAL PAULISTA. Anuário Estatístico da UNESP 2015. São Paulo. Disponível em: https://ape.unesp.br/anuario/pdf/Anuario2015_NOVO.pdf. Acesso em: 20 abr. 2016. 